\title{
Oral health experience during pregnancy and dental service utilization in Bariadi District, Tanzania
}

\author{
IBRAHIM E.A.T. MWANGOSI ${ }^{* *}$ and MARY M. KIANGO ${ }^{2}$ \\ ${ }^{1}$ Muhimbili School of Assistant Dental Officers, Institute of Allied Health Sciences Muhimbili, P. O. Box 66521 \\ Dar es Salaam, Tanzania \\ ${ }^{2}$ Bariadi District Council, Bariadi, Tanzania
}

\begin{abstract}
A substantial proportion of pregnant women reports experiencing oral health problems during pregnancy. However, most of them perceive that such problems are normal in pregnancy and hence do not seek dentist consultation. The objective of this study was to determine the prenatal oral health experience and the utilization of dental care services among pregnant women attending reproductive and child health clinics in Bariadi District in Tanzania. Data was collected using a questionnaire-guided interview. Key variables were socio-demographic characteristics of pregnant women, oral health experience, and dental visits during pregnancy with reasons and treatment received. A total of 305 pregnant women (mean age $=25.7$ years) were involved in the study. Most of the listed oral health problems during pregnancy were reported by women with $2+$ children. The frequent oral health problems among the pregnant women were bleeding gums $(22.6 \%, \mathrm{~N}=69)$, pain in gums $(21.6 \%, \mathrm{~N}=66)$, swollen gums $(21.3 \%, \mathrm{~N}=65)$, dental pain $(30.5, \mathrm{~N}=93)$, and tooth decay $(25.6 \%, \mathrm{n}=78)$. However, only $31.8 \%(\mathrm{~N}=97)$ visited a dental clinic for consultation most whom, were those with three or more children $\left(\chi^{2}=4.682 ; P=002\right)$. The pregnant women who had visited a dentist in the past 12 months were $11.1 \%(\mathrm{~N}=34)$, mostly those aged $>24$ years and those with informal employment $(P<0.05)$. Curative and preventive treatments were received more significantly by the urban and with formal employment $(P<0.01)$. In conclusion, pregnant women in Bariadi, Tanzania experiences substantial oral health problems for which they do not often utilize dentists for consultation and management during pregnancy. Dentists and other health workers should therefore, intensify dental screening, emphasizing active family and community participation as part of regular prenatal care.
\end{abstract}

Keywords: pregnancy, oral health, prenatal, dental visits, Tanzania

\section{Introduction}

Studies have shown that a substantial proportion of pregnant women report that they experience oral health problems involving hard and soft tissues during pregnancy (Murphey \& Fowles, 2010). However, most of them perceive that such problems are normal to a pregnant woman and fade away during post-natal periods (Resler-Maerlender et al. 2005). With such perceptions, most pregnant women abstain from seeking professional dental consultation and/or are reluctant to undergo certain dental procedures during pregnancy with fear of possible harm to themselves or their babies (Ressler-Maerlender et al. 2005; Dinas et al., 2007)). In many situations, oral health screening is not a routine procedure in many antenatal clinics and there are no standard guidelines which ensure that all pregnant women are routinely screened, treated or referred to specialized dental professionals as part of prenatal care (Mills \& Moses, 2002; Zenata et al. 2008). Very often the pregnant women are referred to dentists by obstetricians only when there are complaints by a pregnant woman in relation to oral health (Murphey \& Fowles, 2010). Even when such

\footnotetext{
* Correspondence: Ibrahim E.A.T. Mwangosi; Email: ieatmwangosi@yahoo.com
} 
referrals are made, some dentists are not very happy to attend a pregnant woman; instead they prefer to postpone treatment until after labour (Zenata et al., 2008). Sometimes dentists are reported to be unaware of scientific recommendations on how to manage oral health problems during pregnancy (Pina \& Douglass, 2011). According to Lee et al (2010), there are five perceived barriers, mostly attitudinal, associated with reluctance among dentists from providing dental care to pregnant women. Such barriers include time over-consciousness, economic reasons, deficiency in professional skills, dental staff resistance, and peer pressure (Lee et al., 2010).

Some workers have emphasized on the importance of good oral health in pregnancy, suggesting that it is advantageous to both the mother and her baby (Amin \& Casimassimo, 2010). For instance, maternal periodontal disease has often linked to preterm birth, low birth weight, and preterm low birth weight (Mills \& Moses, 2002; Dasanayake et al. 2008). However, dental care, such as treatment of periodontal disease, is frequently recommended during pregnancy because of the proven safety, effectiveness and its positive oral health behavioural impacts on families, especially when combined with vertical oral health education and oral health promotions (Mills \& Moses, 2002; Dasanayake et al. 2008; Lin et al. 2011). An improvement in oral health status has been reported following treatment of periodontal disease by scaling and root planning (Polyzos et al., 2010).

Oral health experience among pregnant women during pregnancy has been reported from the developed countries (Al Habashnesh et al., 2005; Bogess et al., 2010; Detman et al., 2010). The frequently reported barriers from dental visits include difficulty in finding a dentist, low priority given on dental care, lack of insurance, misconception about safety and appropriateness of dental care during pregnancy, and sporadic anticipatory guidance during prenatal care and financial ability (Huller et al., 2008; Keirse \& Plutzer, 2010; Marchis et al., 2010). On the other hand, factors in favour of dental visits have been described to include personal (married, dental visits outside pregnancy, and use of interproximal aides), financial, and knowledge of possible connection between oral health and pregnancy outcomes (Manskau \& Arrindell, 1996).

Information on oral care among pregnant women in African countries is scarce. For instance, in Nigeria only $36.7 \%$ of pregnant women reported having received oral care information from a dentist (Orenuga \& Sofola, 2005). This study was therefore carried out to explore the level of oral health-related experience during pregnancy among antenatal mothers attending reproductive and child health clinics in a rural district of Tanzania.

\section{Materials and Methods}

\section{Study area, design and data collection}

This descriptive cross-sectional study involved pregnant women attending routine Reproductive and Child Health ( $\mathrm{RCH}$ ) clinics at the District Hospital and Health Centres in Bariadi District in Tanzania during June 2011. All pregnant women attending the clinics and gave their informed consents were enrolled in the study.

A supervised, well structured, questionnaire-guided interview in Kiswahili was used in the study, allowing closed and open responses. Information on the socio-demographic characteristics of the study subjects was collected. These included age (last birth day in years), educational level, and marital status, number of children, residence, and employment status. Educational status was subdivided into informal (any participant without primary education certificate), and formal education (any participant with at least a primary 
educational certificate). Any participant with full-time occupation, earning monthly salaries was considered as employed, whereas part-time occupations with part-time wages were considered as not employed. Participants were asked on whether or not they had ever experienced any oral problems during pregnancy such as dental pain, bleeding gums, pain from gums, and change in colour of gums, toothache, swollen gums, and tooth decay/dental caries. Moreover, participants were asked on the decision against any of the reported oral health problems. The last dental visit with reason for the visit and type of treatment (curative or preventive) received was explored. Furthermore, participants were asked on whether or not they ever received oral hygiene instructions and oral health education from dental practitioners during pregnancy.

\section{Data analysis}

Data were compiled, organized and recorded in the computer SPSS files version 11.0 for analysis. For the purpose of analysis, data were recorded by dichotomizing whenever necessary. Frequency statistics and cross tabulations were done, Chi-square test was used to test for statistic significance at the critical value $\mathrm{p}<0.05$.

\section{Ethical considerations}

The Muhimbili University of Health and Allied Sciences approved the study. Permission to access the study clinics was sought from the District Executive Director, the District Medical Officer, and from the District Co-coordinator of the Reproductive and Child Health. All ethical considerations were closely observed including verbal and written consent from the would-be participants with detailed explanation on the study protocol. Arrangement was made to ensure that every participant in need of oral health care was attended by a dentist.

\section{Results}

A total of 305 pregnant women, with the mean age $25.7 \pm 6.2$ years (mode 20 years) were involved in the study. Significantly more women with three children or more than those with two or less children had hard and soft tissue dental related problems during pregnancy $(P<0.05)$. Generally, the experienced oral health problems among the pregnant women were bleeding gums $(22.6 \%, \mathrm{n}=69)$, pain in gums $(21.6 \%, \mathrm{n}=66)$, swollen gums $(21.3 \%, \mathrm{n}=65)$, dental pain $(30.5, \mathrm{n}=93)$, and tooth decay $(25.6 \%, \mathrm{n}=78)$. However, only $31.8 \%(\mathrm{~N}=97)$ visited a dental clinic for consultation most of whom, were those with three or more children $\left(\chi^{2}=4.682 ; P=002\right)$. 
Table 1: Frequency distribution in number and percentage (\%) of the antenatal women in the study according to socio-demography $(\mathrm{N}=305)$

\begin{tabular}{llll}
\hline Variable & Response & Frequency (N) & Percent \\
\hline Age & $\leq 24$ years & 153 & 50.2 \\
& $>24$ years & 152 & 49.8 \\
Residence & Urban & 196 & 64.3 \\
\multirow{4}{*}{ Number of children } & Rural & 109 & 35.7 \\
& Two or less & 169 & 55.4 \\
& Three or more & 136 & 44.6 \\
Educational status & Primary or less & 262 & 85.9 \\
& Secondary or more & 43 & 14.1 \\
\hline
\end{tabular}

A total of 80 (94.1\%) pregnant women had visited a dentist for curative need and only five (5.9\%) for preventive need. Of those who visited a dentist, significantly more urban than rural participants went for curative and preventive reasons $(P<0.01)$. Generally were those with employment than otherwise (Table 3). On the contrary, significantly more proportion of the older participants ( $>24$ years) were offered curative and preventive treatment compared to their counterparts $(\leq 24$ years) $(P<0.01)$ (Table 4$)$. The urban pregnant women were offered preventive treatment significantly more than the rural $(P<0.01)$. The employed and women with $>2$ children had relatively less often offered preventive treatment than their counterparts.

Table 2: Number and percent of respondents on their dental experiences in previous pregnancy

\begin{tabular}{|c|c|c|c|c|c|c|}
\hline \multirow{2}{*}{$\begin{array}{l}\text { Experiences in previous } \\
\text { pregnancy }\end{array}$} & \multicolumn{2}{|c|}{ Age groups } & \multicolumn{2}{|c|}{ Employment } & \multicolumn{2}{|c|}{ Residence } \\
\hline & $\begin{array}{l}\leq 24 \\
\text { years }\end{array}$ & $>24$ years & Full time & $\begin{array}{l}\text { Not full } \\
\text { time }\end{array}$ & Urban & Rural \\
\hline $\begin{array}{l}\text { Visited dental clinic during } \\
\text { pregnancy }\end{array}$ & $\begin{array}{l}33 \\
(10.8 \%)\end{array}$ & $64(21.0)^{*}$ & $52(17.0)$ & $45(14.8)^{*}$ & $77(25.2)$ & $20(6.6)^{*}$ \\
\hline $\begin{array}{l}\text { Received oral hygiene } \\
\text { instruction }\end{array}$ & $15(4.9)$ & $25(8.2)^{*}$ & $17(5.6)$ & $23(7.5)^{*}$ & $32(10.5)$ & $8(2.6)^{*}$ \\
\hline $\begin{array}{l}\text { Received oral health } \\
\text { education }\end{array}$ & $12(3.9)$ & $20(6.6)^{*}$ & $13(4.3)$ & $19(6.2)^{*}$ & $27(8.9)$ & $5(1.6)^{*}$ \\
\hline Experienced dental pain & $37(12.1)$ & $56(18.4)^{*}$ & $58(19.0)$ & 35 (11.5) & $68(22.3)$ & $25(8.2)^{*}$ \\
\hline Experienced bleeding gums & $24(7.9)$ & $45(14.8)^{*}$ & $34(11.1)$ & $35(11.5)^{*}$ & $54(17.7)$ & $15(4.9)^{*}$ \\
\hline Experienced pain from gums & $19(6.2)$ & $47(15.4)^{*}$ & $32(10.5)$ & $34(11.1)$ & $50(16.4)$ & $16(5.2)^{*}$ \\
\hline Experienced swollen gums & $18(5.9)$ & $47(14.4)^{*}$ & $33(10.8)$ & $32(10.5)^{*}$ & $49(16.1)$ & $16(5.2)^{*}$ \\
\hline Experienced tooth decay & $29(9.5)$ & $49(16.1)^{*}$ & $43(14.1)$ & $32(11.5)$ & $57(18.7)$ & $21(6.9)^{*}$ \\
\hline $\begin{array}{l}\text { Took correct management } \\
\text { measure }\end{array}$ & $16(5.2)$ & $38(12.5)$ & $33(10.8)$ & $21(6.9)$ & $42(13.8)$ & $12(3.9)^{*}$ \\
\hline $\begin{array}{l}\text { Had at least one dental visit } \\
\text { in last } 12 \text { month }\end{array}$ & $11(3.6)$ & $23(7.5)^{*}$ & $16(5.2)$ & $18(5.9)$ & $26(8.5)$ & $8(2.6)$ \\
\hline
\end{tabular}

${ }^{*} P<0.05$; NB. For the purpose of analysis, the total number of respondents who had experienced a characteristic in question formed the denominator; those who did not experience a questioned experience were not included in the denominator across age groups, employment status and residence. Each variable has its own denominator across age groups, employment status and residence

Table 3: Number (percent) of respondents on reasons for dental visits

Reasons for dental Residence $\quad$ Occupation $\quad$ Total




\begin{tabular}{llllll}
\hline visit & \multicolumn{5}{l}{} \\
\hline & Urban & Rural & Employed & Unemployed & \\
Curative & $62(72.9)$ & $18(21.2)$ & $42(49.4)$ & $38(44.7)$ & $80(94.1)^{*}$ \\
Preventive & $4(4.7)$ & $1(1.2)$ & $4(4.7)$ & $1(1.2)$ & $5(5.9)$ \\
Total & $66(77.6)$ & $19(22.4)$ & $46(54.1)$ & $39(45.9)$ & $85(100)$ \\
\hline${ }^{*} P<0.05 ;$ Curative reasons were defined to include toothache and bleeding gums; whereas preventive reasons \\
included check up and treatment follow up.
\end{tabular}

Table 4: Number and percent (\%) of participants who reported the type of treatment offered

\begin{tabular}{llllllll}
\hline Variable & Response & \multicolumn{2}{l}{ Curative } & \multicolumn{3}{c}{ Preventive } & \multicolumn{2}{l}{ Total } \\
& & No. & $\%$ & No. & $\%$ & No. & $\%$ \\
\hline Age (years) & $\leq 24$ & 25 & 30.5 & 4 & 4.9 & 29 & $35.4^{*}$ \\
& $>24$ & 40 & 48.8 & 13 & 15.9 & 53 & $64.6^{*}$ \\
Residence & Urban & 49 & 59.8 & 15 & 18.3 & 64 & $78.0^{*}$ \\
& Rural & 16 & 19.5 & 2 & 2.4 & 18 & 22.0 \\
Occupation & Unemployed & 29 & 35.4 & 10 & 12.2 & 39 & 47.6 \\
& Employed & 36 & 43.9 & 7 & 8.5 & 43 & 52.4 \\
No. children & $\leq 2$ & 31 & 37.8 & 9 & 11.0 & 40 & 48.8 \\
& $\geq 2$ & 34 & 41.5 & 8 & 9.8 & 42 & 51.2 \\
Total & No & 65 & 79.3 & 17 & 20.7 & 82 & 100 \\
\hline
\end{tabular}

${ }^{*} P<0.05$; Curative treatment type was defined to include tooth filling, extraction and medications; whereas preventive treatment included oral hygiene instruction only.

\section{Discussion}

The fact that multi-parity and the married women had significantly more oral health related problems could in part or completely signify the paucity of access to oral health professional hands among pregnant women as part of prenatal care. It also suggests inadequacy of active involvement of the partners and family members who would prioritize and participate on reproductive health issues in prenatal care in terms of readiness to bear some cost (Orenuga \& Sofola, 2005; Marchi et al. 2007; Detman et al. 2010; Lee et al., 2010; Keirse \& Plutzer, 2010; Lin et al. 2011). However, despite of distant cultural and economic differences from the developed countries, the current study suggest a homogenous pattern of oral health arena in pregnant women during pregnancy. A quarter of the pregnant women in this study had oral hard and soft tissue problems but only a third of pregnant women consulted a dentist (Dinas et al. 2007; Resler-Maerlender et al. 2008; Marchi et al. 2010; Keirse \& Plutzer, 2010; Boggess et al. 2010). In this study, having multiple children significantly determined the frequency of visits to a dental clinic.

Although a substantial proportion (30.5\%) of the pregnant women experienced dental problems, only $17.7 \%$ took correct measures of consulting a dentist, significantly driven by having less education than otherwise. This is consistent with findings in studies carried out elsewhere (Dinas et al. 2007; Hullah et al. 2008). This suggest possibility for the more educated pregnant women to have alternatively better options probably due to better economic status and sharper quality concern on the anticipated dental service available (Al Habashneh et al. 2005).

The most frequently offered dental treatment to $27.9 \%$ of the pregnant women who had visited a dentist was curative among less than a quarter. This study significantly shows that the pregnant women who received preventive dental care were from urban than rural. Most of those with formal employment received curative treatment. On the contrary, a large 
proportion of the pregnant women did not seek for professional dental consultation at all. According to Sarita \& Tuominen (1993), people vices than otherwise live far from the oral health care services are not likely to be good users of oral health care service, instead they depend on home remedies and traditional healers in early forms of the problems. It seems the perceived oral health needs on the part of the patients are not necessarily the normative needs on the part of the professionals, probably because professionals have scientific guidelines of management that might not necessarily be accepted by patients.

Contrary to the findings by Keirse \& Plutzer (2010), the current study has shown in many explored aspects, that significantly more of the pregnant women who were older ( $>24$ years), informal income, from urban than rural, reported that they had experienced dental pain and decay during pregnancy; had signs of gingivitis during pregnancy (painful, swollen, and bleeding gums); recalled having received oral health education and oral hygiene instruction by a dentist; took correct measures of consulting a dentist; and visited a dentist at least once in the past 12 months (Keise \& Plutzer, 2010).

Other studies have shown that some women were not aware of the existence of free dental prenatal services even among the multi-gravid women (Manger \& Arrindel 1996; Huller et al., 2005). This was driven by the women's ignorance about oral health status in which oral health related problems were considered normal to a pregnant woman (Keirse \& Plutzer, 2010); and the wrong perception over dental treatment during pregnancy in which pregnant women perceive likely to encounter consequential harm to themselves or their foetuses. These factors jeopardize prenatal health of pregnant women as seen in other studies (Murphey \& Fowles, 2010).

According to Orenuga \& Sofola (2005) in Nigeria, only about one third of the pregnant women reported having received oral care information from a dentist. On the other hand, Detman et al. (2010) in Florida USA reported that most pregnant women did not obtain dental care and did not recall to have received any dental information during prenatal visits. The current study has shown only $10.5 \%$ and $13.1 \%$ of the pregnant women recalled to have received $\mathrm{OHE}$ and $\mathrm{OHI}$ from a dentist respectively when pregnant.

Well planned prenatal dental care services in the form of routine screening for early detection and management of dental problems during pregnancy along with logical oral health education and oral hygiene instructions are frequently advocated (Al Habashneh et al. 2005; Mills \& Moses, 2002;). These forms of remedies have been proved efficient and safe to any pregnant woman and are worth understanding by the public and health professionals alike (Mills \& Moses, 2002; Resler-Maerlender et al. 2005; Dinas et al. 2007).

In conclusion, pregnant women experiences substantial oral health problems for which they do not often utilize dentists for consultation and management during pregnancy. Oral health professionals should therefore, strengthen the routine oral health screening, needful treatment on top of vertical oral health education and oral hygiene instruction with emphasizes that influence active participation of family members and other health workers as part of basic prenatal care.

\section{References}

Al Habashnesh, R., Guthmiller, J.M., Levy, S., Johnson, G.K., Squier, C., Dawson, D.V. \& Fang, Q. (2005) Factors related to utilization of dental services during pregnancy. Journal of Clinical Periodontology 32, 815-21. 
Boggess, K.A, Urlaub, D.M., Massey, K.E., Moos, M.K., Matheson, M.B. \& Lorenz, C. (2010) Oral hygiene practice and dental service utilization among pregnant women. Journal of American Dental Association 141, 553-61.

Dasanayake, A.P., Gennaro, S., Hendricks-muñoz, U.D. \& Chhun, N. (2008) Maternal periondontal disease, pregnancy and neonatal outcomes. MCN American Journal of Maternal and Child Nursing 33, 45-49.

Detman, L.A., Cottrel, B.H. \& Denis-Luque, M.F. (2010) Exploring dental care misconceptions and barriers in pregnancy. Birth 37, 318-24.

Dinas, K., Achyropoulos, V., Hatzipantelis, E., Mavromatidis, G., Zepiridis, L., Theodoridis, T., Dovas, D., Tantanasis, T., Goutzioulis, F. \& Bontis, J. (2007) Pregnancy and oral health: utilization of dental services during pregnancy in Northern Greece. Acta Obstetricia et Gynecologica Scandinavica 86, 938-944.

Hullar, E., Turok, Y., Nauta, M. \& Yoong, W. (2008) Self-reported oral hygiene habits, dental attendance and attitudes to dentistry during pregnancy in a sample of immigrant women in North London. Archives of Gynecology and Obstetrics 277, 405-409.

Keirse, M.J. \& Plutzer, K. (2010) Women's attitudes to and perceptions of oral health and dental care during pregnancy. Journal of Perinatal Medicine 38, 3-8.

Lee, R.S., Milgrom, P., Huebner, C.E. \& Conrad, D.A. (2010) Dentist's perceptions of barriers to providing dental care to pregnant women. Women's Health Issues 20, 359-365.

Lin, D.L., Harrison, R. \& Aleksejuniene, J. (2011) Can a perinatal dental public health program make a difference? Journal of Canadian Dental Association 77, b32.

Mangskau, K.A. \& Arrindell, B. (1996) Pregnancy and oral health: utilization of the oral health care system by pregnant women in North Dakota. Northwest Dentistry 75, 2328.

Marchi, K.S., Fisher-Owen, S.A., Weindraub, J.A., Yu, Z. \& Braveman, P.A. (2010) Most pregnant women in California do not receive dental care: findings from a population based study. Public Health Report 125, 831-842.

Mills, L.W., \& Moses, D.T. (2002) Oral health during pregnancy. MCN American Journal of Maternity and Child Nursing 27, 275-280.

Murphey, C. \& Fowles, E. (2010) Dental health, cariogenic meal and snack patterns among low-income women during early pregnancy: a pilot study. Journal of Midwifery and Women's Health 55, 587-592.

Orenuga, O.O. \& Sofola, O.O. (2005) A survey of knowledge, attitude and practices of antenatal mothers in Lagos Nigeria about the primary teeth. African Journal of Medicine and Medical Sciences 34, 285-291.

Pina, P.M. \& Douglass, J. (2011) Practices and opinions of Connecticut general dentists regarding dental treatment during pregnancy. General Dentistry 59, e25-31.

Ressler-Maerlender, J., Krishna, R. \& Robison, V. (2005) Oral health during pregnancy: current research. Journal of Woman's Health (Larchmt) 14, 880-882.

Sarita, P.T., Tuominen, R. (1993) Use of health care services in two rural communities in Tanzania. Community Dentistry and Oral Epidemiology 21, 133-5.

Zenata, R.L., Fernandes, K.B. \& Navarro, P.S. (2008).Prenatal dental care: evaluation of professional knowledge of obstetricians and dentists in the cities of Londrina/PR and Bauru/SP, Brazil, 2004. Journal of Applied Oral Science16, 194-200. 